\title{
Experimental Study on Fly Ash for Conditioning of Specific Resistance of Sludge Water
}

\author{
Bingtao Liu, Pengju Ding \\ School of Environmental and Municipal Engineering, North China University of Water Resources and Electric \\ Power, Zhengzhou, China \\ Email: liubingtao@ncwu.edu.cn
}

Received August 2013

\begin{abstract}
Discharge of sludge from water works into waters will result in the increased deterioration of water environment. Therefore, an experimental study was conducted on the addition of conditioning agent to improve sludge dewatering performance. The result shows that coagulation is inadaptable to the treatment of sludge from water works and use of powdered coal ash from power plant as conditioning agent can greatly reduce the specific resistance of sludge and the dewatering performance can be improved. The optimal dosage of fine powdered coal is $20 \mathrm{~g} / 100 \mathrm{~mL}$ and coarse powdered coal is $30 \mathrm{~g} / 100 \mathrm{~mL}$. Powdered coal is mixed with sludge to form filter cake, which is blended with coal in certain proportion to make into fuel. So that incineration of sludge from water works can be realized.
\end{abstract}

Keywords: Fly Ash; Sludge Water; Sludge; Specific Resistance

\section{Introduction}

The sludge water of waterworks includes sludge water of settling tank and backwash wastewater of filter. After the simple sedimentation and separation, the supernatant can be reused, sediment forms so-called sludge of sludge water. At present, most of the existing waterworks directly discharge sludge of sludge water into natural water in China which will cause pollution to water (Liu Hui \& Xu Jianhua, 2001; Lu jiajuan, 2005).

In the 1970s, the United States, Japan and other developed countries began to pay attention to the treatment and disposal of sludge of waterworks (John T. Novak, 1999; J Kopp \& N Dichtl, 2001). The treatment method is similar to sludge treatment method of municipal sewage plant (Xu Qiang, 2003). However, the sludge from waterworks and sewage plant has different characteristics, even if the sludge is all from waterworks. There are significant differences in properties because of the different raw water quality and the different production technology. We have an experimental research on methods of treatment and disposal of sludge from inclined tube sedimentation tank of water treatment plant in Zhengzhou.

\section{Experiment}

\section{Main Reagents and Mud Sample}

PAC, light yellow powder, alumina content $31 \%$, basicity $76 \%$, confect concentration of $10 \mathrm{~g} \cdot \mathrm{L}^{-1}$ when use it.

Sludge samples, Activated sludge from Zhengzhou city sewage sludge treatment plant emissions, take underlayer precipitation after standing.

Two kinds of fly ash that contains fly ash of coarse particle and fine particle in the experiment are from Zhengzhou thermal power plant. Its quality is shown in Table 1.

\section{Experiment Method}

Test is divided into two steps. First of all is test of coagula-
Table 1.

Quality index of powdered fly ash (\%).

\begin{tabular}{ccc}
\hline Items & $\begin{array}{c}\text { Finenes } \\
\text { (Remaining amount of } 45 \mu \mathrm{m} \text { screen) }\end{array}$ & $\begin{array}{c}\text { Burning } \\
\text { loss }\end{array}$ \\
\hline Fly ash of coarse particle & 55.2 & 4.41 \\
Fly ash of fine particle & 12.9 & 3.13 \\
\hline
\end{tabular}

tion, sedimentation and pre-concentration of waterworks sludge is in progress and we can obtain settlement curve. Then specific resistance of mud sample is measured (an important index of sludge dewatering performance) and make optimization of the sludge conditioner of specific resistance in order to achieve the sludge dehydration and drying.

The purpose of adding $1 \mathrm{~g}$ PAC and $5 \mathrm{mg}$ PAM coagulant to per liter of sludge water is to destabilize colloids that inorganic coagulant is the first dosing and PAM is dosing after $5 \mathrm{~S}$. Operating parameters: in the mixing process, $n=300 \mathrm{r} / \mathrm{min}, \mathrm{T}=30$ $\mathrm{S}$; in the flocculation process, $\mathrm{n}_{1}=150 \mathrm{r} / \mathrm{min}, \mathrm{T}_{1}=3 \mathrm{~min}, \mathrm{n}_{2}=$ $30 \mathrm{r} / \mathrm{min}, \mathrm{T}_{2}=10 \mathrm{~min}$. Static precipitation continues for $2 \mathrm{~h}$ after coagulation, a decline height of muddy liquid level along with time is recorded and subsidence curves is depicted.

Specific resistance has a special measuring device shown in Figure 1. Including Büchner funnel, filter media, smoke filters, cylinders, vacuum table and vacuum pump.

Test run at room temperature. Measure out $100 \mathrm{ml}$ of sludge in the beaker, stir in a certain $\mathrm{pH}$ by adding flocculents, stir in medium-speed about 5 minutes and pour into the Büchner funnel, the vacuum filtration dehydration until no drop. Then record at different times (t) and the corresponding filtrate volume (v), with $t / v$ as the vertical coordinate, $v$ the horizontal mapping, $t / v$ and $\mathrm{v}$ is linear, the slope $b$, constant pressure filtration

$$
\gamma=\frac{2 P A^{2} b}{\mu C}
$$

Where 


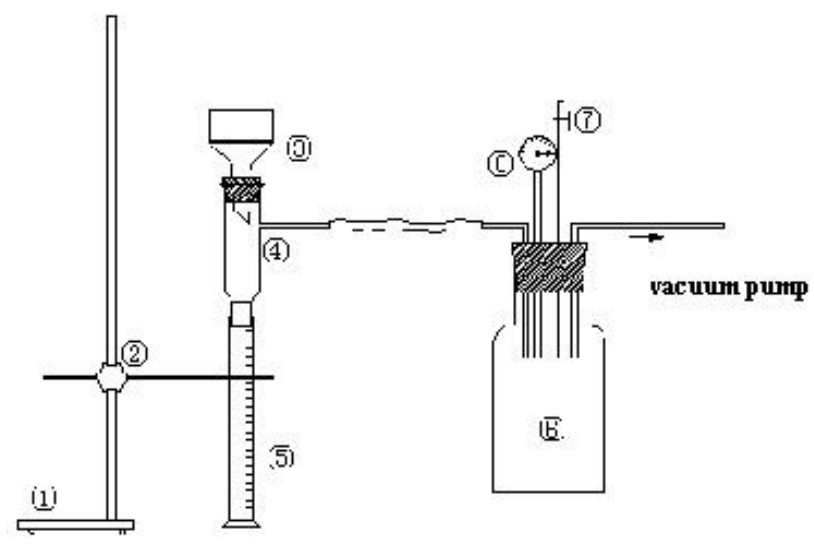

1 hob, 2. clant, 3 . filler, 4 . linker, 5 measuring cylinder, 6.jar, 7.drain tap, 8. vacuometer

Figure 1.

Experimental set of specific resistance measurement.

$P$ : filtration pressure (for the cake pressure difference between top and bottom surfaces), $\mathrm{N} \cdot \mathrm{m}^{-2}$

A: filter media area, $\mathrm{m}^{2}$

$b$ : filtration time/filtrate volume and filtrate volume formed by the slope, $\mathrm{s} \cdot \mathrm{m}^{-6}$

$\mu$ : filtrate dynamic viscosity, (N.s) $\cdot \mathrm{m}^{-2}$

$C$ : filter biscuits dry quality by the filtrate, $\mathrm{kg} \cdot \mathrm{m}^{-3}$, according to the weight of dry solid and the filtrate volume by filtrate to calculate.

We can calculate the specific resistance of sludge and measure its filtrate turbidity, filtration time and filtrate volume, and needed time to get same filtrate. Sludge dewatering performance reflect by the specific resistance, the greater the value the worse the dehydration properties. By contrary, dehydration performance is better.

At present, in order to improve dewatering performance of the sludge of waterworks, sludge usually be added the right amount of polyacrylamide (PAM) to reduce specific resistance of sludge before its mechanical dehydration. But PAM exists many problems in practice. Firstly the price is expensive. It cannot reach to the effect of reducing specific resistance when dosage is insufficient and dosage is more and it will make the operation cost become too high. Secondly PAM is a kind of viscous slurry. It is easy to stick on the cloth filter and choke filtration pore which affects the dehydration efficiency. So the material such as fly ash of power plant is chosen as a conditioner. Optimization experiment is carried out in order to improve the separation efficiency and reduce the production cost.

\section{Results and Discussion}

\section{Curve of Natural Sedimentation and Coagulation Sedimentation}

Settlement curve can be seen by Figure 2, Whether the natural sedimentation of original sludge water or static precipitation under optimum amount of coagulant, the drop height of muddy liquid are not very satisfactory, which decrease by only $3.2 \%, 4.0 \%$ and $8.1 \%$, respectively, thus we need not set up the coagulation process when we design the process of sludge water treatment for waterworks, only set up an intermediate regu-

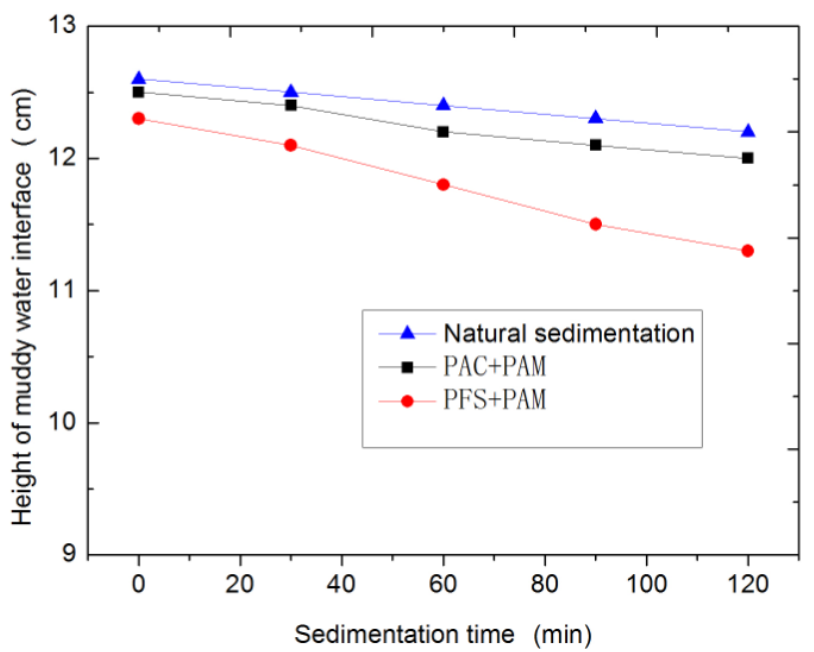

Figure 2.

Settlement curve of sludge water.

lating pond, and preliminary sinking separation pool is not necessary.

\section{Specific Resistance Conditioning Curve of Sludge}

Measurement results of specific resistance of original sludge are shown in Table 2. Literature Novak J indicates that, generally speaking, when the specific resistance $<10^{11} \mathrm{~m} / \mathrm{kg}$, sludge is easy to dewater, and specific resistance $>10^{13} \mathrm{~m} / \mathrm{kg}$, sludge dewatering becomes difficult. It is obvious that original sludge dewatering is difficult, suction filtration time is long, and it needs to be conditioning.

Figure 3 shows that specific resistance of sludge decrease quickly with the increase of dosage of fly ash from the pretreatment magnitude of $10^{13}$ to $10^{10}$. When the dosage of fly ash increased to $30 \mathrm{~g}$ per $100 \mathrm{ml}$ of mud sample, the curve tend to gentle. In the case of low dosage, that the effect of improving sludge dewatering performance for fine fly ash is more obvious than coarse fly ash, with the increase of dosage of fly ash, the ability of improving specific resistance for the coarse and fine fly ash tend to be the same. In the measurement experiment of specific resistance, the linear slope (b) formed by filtering time/ filtrate volume and filtrate volume can indirectly reflect the speed of filtration rate, the smaller of the value of $b$, the greater of the speed of filtration rate. The results show that, the value of b drops rapidly with the increase of the dosage of fly ash (the filtration rate increases rapidly), when the dosage of coarse fly ash is $30 \mathrm{~g}$ or the dosage of fine fly ash is $20 \mathrm{~g}$, the speed of filtration rate is the largest, after that, the filtration rate is decreased with the increase of the dosage of fly ash.

\section{The Amplification Test under the Optimal Dosage}

According to the front of the test results, it shows that the optimum dosage of coarse fly ash and fine fly ash is $30 \mathrm{~g} / 100$ $\mathrm{ml}$ and $20 \mathrm{~g} / 100 \mathrm{ml}$ of sludge, respectively. The optimal dosage of sludge dewatering performance and the nature of the filtrate are shown in Table 2.

From Table 3, we can know that the specific resistance of sludge decreases rapidly and the speed of filtration rate increases significantly after the conditioning of fly ash, the suction filtration can be completed in about 3 minutes, and the 
Table 2.

Specific resistance measurement of original sludge.

\begin{tabular}{ccccc}
\hline Items & Suction filtration time $/ \mathrm{S}$ & Filtrate volume $/ \mathrm{ml}$ & Moisture content of filter cake $/ \%$ & specific resistance $/ 10^{13} \cdot \mathrm{m}^{\mathrm{k}} \mathrm{kg}$ \\
\hline Numeric value & 930 & 94.5 & 92.25 & 1.92 \\
\hline
\end{tabular}

Table 3.

Dewatering performance and filtrate quality at optimum dosage.

\begin{tabular}{ccccccccc}
\hline Conditioning dose & Dosage (g) & $\begin{array}{c}\text { Specific resistance } \\
\left(10^{11} \mathrm{~m} / \mathrm{kg}\right)\end{array}$ & $\begin{array}{c}\text { Filtering } \\
\text { time }(\mathrm{s})\end{array}$ & $\begin{array}{c}\text { Filtrate } \\
\text { volume (ml) }\end{array}$ & $\begin{array}{c}\text { Moisture content } \\
\text { of filter cake (\%) }\end{array}$ & $\begin{array}{c}\text { Filtrate turbidity } \\
(\mathrm{NTU})\end{array}$ & $\begin{array}{c}\text { Chromaticity } \\
\text { of filtrate (NCU) }\end{array}$ & $\begin{array}{c}\text { COD } \\
\text { of filtrate (mg/L) }\end{array}$ \\
\hline Coarse fly ash & 30 & .50 & 160 & 70 & 41.12 & 4 & 42 & 16.00 \\
Fine fly ash & 20 & .70 & 200 & 75 & 47.80 & 4 & 23 & 15.04 \\
Amplification of 1 & 1500 & .45 & 140 & 73 & 40.04 & 4 & 30 & 20.77 \\
Amplification of 2 & 1000 & .80 & 220 & 80 & 47.96 & 4 & 28 & 17.45 \\
\hline
\end{tabular}

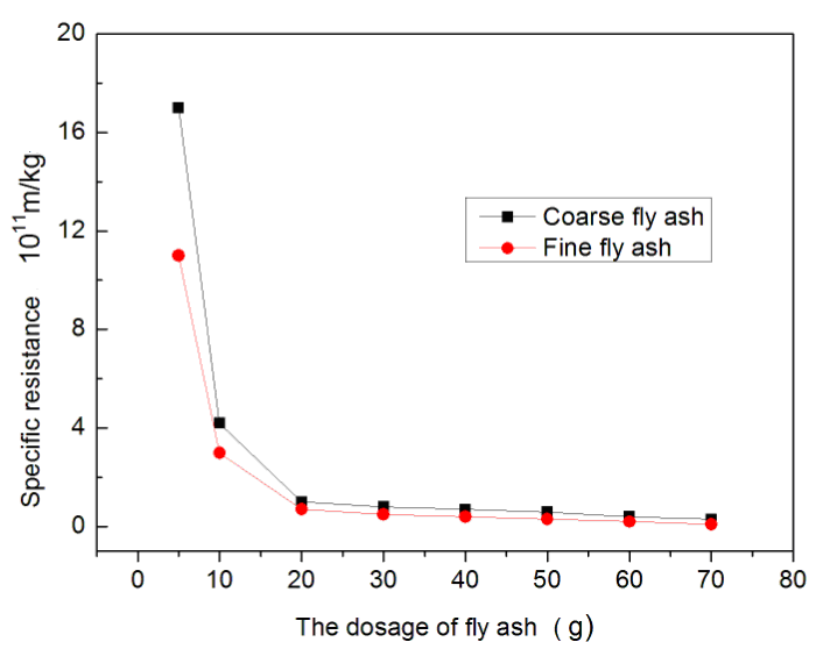

Figure 3.

Effect of Sludge specific resistance.

filter cake is dry, it is easy to strip from the filter paper, the value of filtrate turbidity, chromaticity and $\mathrm{COD}_{\mathrm{Mn}}$ is not high, it can be used as municipal miscellaneous water.

Ignition loss is due to the unburned carbon particles burning again in the laboratory. The ignition loss in the filter cake formed by the fine fly ash after dehydration is $6.47 \%$, and ignition loss of fine fly ash is only $3.13 \%$, so it can be inferred that the increase combustible comes from combustible components of the sludge. It can be taken use of, for example, it can be made of blend coal cake through mixing with proportion coal, which is available for civilian or power boiler burning, so as to achieve the final incineration disposal of sludge.

\section{Analysis Results of Scanning Electron Microscope}

The section of filter cake of original mud and conditioning is sprayed gold, then scanning electron microscope is carried out. The results are shown in figure. The sludge particle size of sludge water is very small, about the quality of $76 \%$ of particle size is less than 4 microns, so the channel of filter cake formed is small (Fei Xiali \& Cui Fuyi, 2004). In addition, there is a layer of hydration shell in granular bed of filter cake whose flowability is poor. It can be seen from Figure 4. The filter cake gap of original sludge is very small and it will make filtration resistance increases and the fly ash is a variety of mechanical mix-

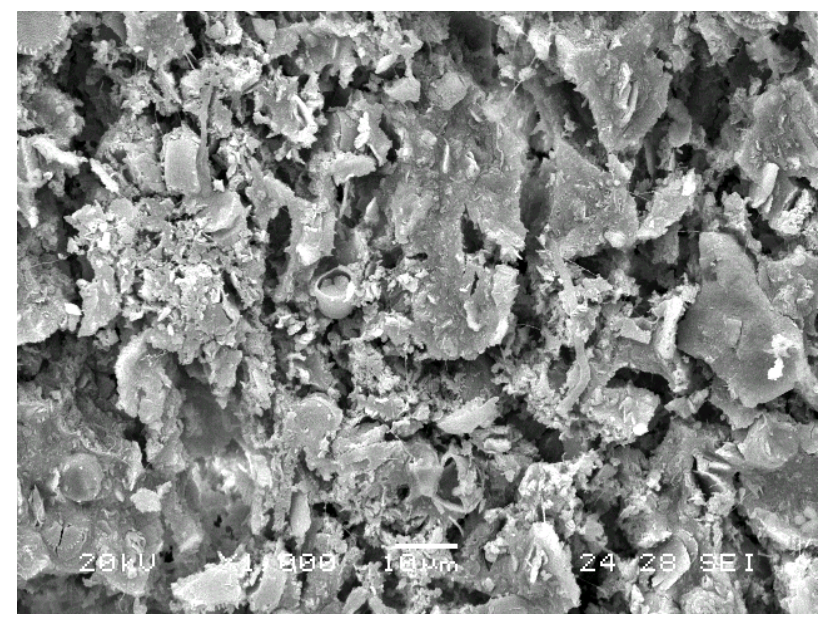

Figure 4.

SEM appearance made from original sludge.

ing of powder particles. Generally the particle size is more than 30 microns due to the unique structural characteristics of fly ash. The mud sample of conditioning can be used as a skeleton which make the sludge flocs form the structure of persistence and strong. The channel of filter cake is larger, which can form the solidified layer of loosened structure and increase the void fraction as is shown in Figures $\mathbf{5}$ and $\mathbf{6}$. At the same time, the carbon that is not burning enough and porous vitreous content of fly ash is less, the content of glass beads is more, it is not easy to store water for caves and gap of sphere but coarse fly ash is instead, so in the case of low additive amount of fly ash, fine fly ash is better to the improvement of the sludge dewatering effect.

\section{Conclusion}

When the sludge of sludge water of waterworks carries on the treatment of dewatering and drying, it is better to choose fly ash as conditioners (filter aid). In the process design of treatment of sludge water of waterworks, we need not set up the coagulation process, and only set up an intermediate regulating pond. It is easy to dewater for the sludge of waterworks that have been conditioning by fly ash, mud cake that comes from the process of filter-press and suction filtration is mixed with coal to make coal cake, which can realize the final incineration disposal. 


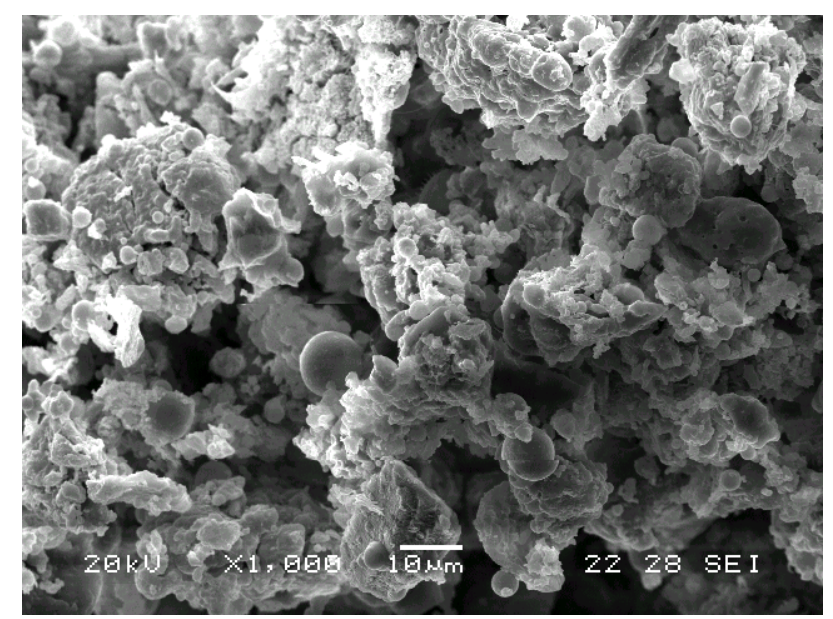

Figure 5.

SEM appearance by coarse fly ash.

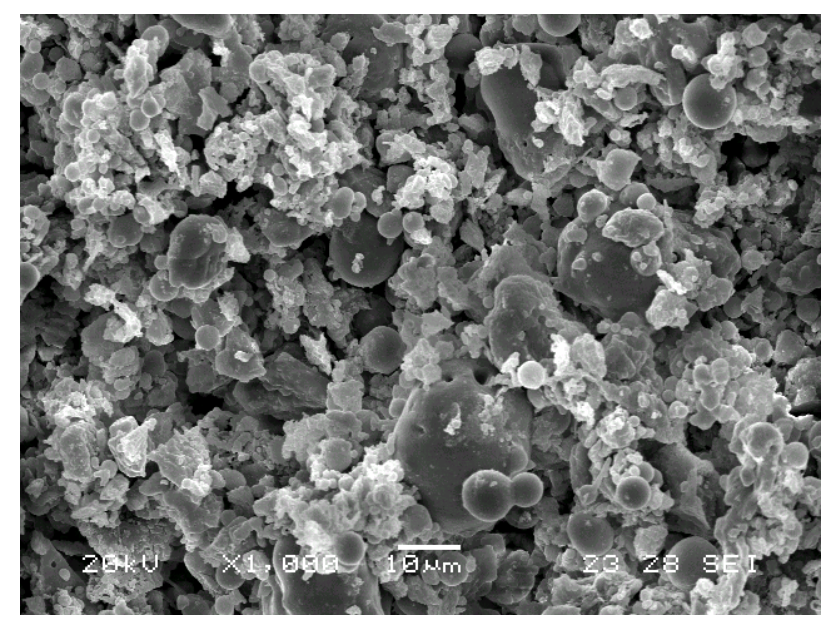

Figure 6.

SEM appearance by fine fly ash.

\section{Acknowledgements}

We thank the financial support by North China University of Water Resources and Hydroelectric Power.

\section{REFERENCES}

Liu, H., \& Xu, J. H. (2001). Survey on the development of sludge water treatment in waterworks at home and abroad. China Water and Wastewater, 17, 24-26.

Novak, J. T., \& Mark, L. (1977). The use of polymers for improving chemical sludge dewatering on sand bed. AWWA, 69, 106-109.

Lu, J. J., Wang, Y. L., Hou, L., et al. (2005). Fractal characteristics and scale dependence of mature granular sludge in anaerobic baffled reactor (ABR). Environmental Science, 26, 119-123.

John, T. N. (1999). Conditioning, filtering and expressing waste activated sludge. Journal of Environmental Engineering, 125, 816-824. http://dx.doi.org/10.1061/(ASCE)0733-9372(1999)125:9(816)

Kopp, J., \& Dichtl, N. (2001). Prediction of full-scale dewatering results of sewage sludge by the physical water distribution. Water Science Technology, 43, 135-143.

$\mathrm{Xu}$, Q., Zhang, C. M., \& Zhao, L. J. (2003). The technology and equipment of sludge disposal. Beijing, Chemical Industry Press, 1926.

Fei, X. L., \& Cui, F. Y. (2004). Experimental research on sludge dewatering property at waterworks in Xiamen City. Water and Wastewater Engineering, 4, 1-5. 